\title{
Design of Web-based Management Information System for Academic Degree \& Graduate Education
}

\author{
Rui Duan ${ }^{1}$, Mingsheng Zhang ${ }^{2}$

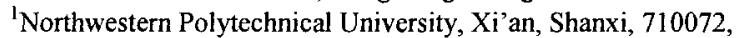 \\ duanrui@mail.ccnu.edu.cn \\ ${ }^{2}$ Huazhong Normal University, Wuhan, Hubei, 430079, \\ mszhang@mail.ccnu.edu.cn
}

\begin{abstract}
For every organization, the management information system is not only a computer-based human-machine system that can support and help the administrative supervisor but also an open technology system for society. It should supply the interaction function that face the organization and environment, besides gather, transmit and save the information. The authors starts with the intension of contingency theory and design a web-based management information system for academic degree \& graduate education which is based on analyzing of work flow of domestic academic degree and graduate education system. What's more, the application of the system is briefly introduced in this paper.
\end{abstract}

\section{Introduction}

In college and university, the all functions and whole process of management are an open system of general management. It includes the academic record management, cultivating scheme management, course management, grade management, degree management and directing the students to take up an occupation, etc. Every function department involved in the system has respective special information requirements and there are diversified information connections among them. "The web-based management information system for academic degree $\&$ graduate education" is based on the contingency theory and tries to more efficiently manage the academic degree $\&$ graduate education from the interrelation and dynamic activity in system. 


\subsection{Known Results}

The basic assume of contingency theory is organization, environment and every subsystem should achieve consistency. The contingency viewpoint is a systemic concordant thought and can solve problems. These thought let manager starts with whole and carry on management with the aim of realize the whole target. Its significance is focusing on that change of management is consistent with the change of people, time, place and environment. It focuses that using different strategy in change environment.

Management Information System, namely MIS, is a human-machine system that uses systemic thinking and has the modern communication techniques as the basic information disposal means and transfer tools. It can supply the information service to managers. MIS is a unified system or integrated system, that is to say MIS carries on the management staring with the whole status, entirely considers every factor and ensures the share datum in each function department, in order to decrease the data redundancy and ensure data compatibility and consistency.

One the one hand, the application of web-based management information system decreases the middle-level management layers and makes the structure of organization more flat; on the other hand, it strengthens the communication channel of inter-organization. At the same time, it makes the application system quicker and reduces the cost.

The web-based management information system for academic degree \& graduate education utilizes the $\mathrm{B} / \mathrm{W} / \mathrm{D}$ structure. The work principle of traditional $\mathrm{C} / \mathrm{S}$ structure is user puts forward data requirement to client computer by application, client computer puts in the requirement to server by network, server' database management system execute the data processing mission, and then the datum that user needed are transmitted to client computer, finally, client computer completes the processing of the needed datum. However, in B/W/D structure it is just need to install a Browser on client computer, middle-layer of system utilizes web server. The web server acts as not only an agent of client but also a client of database. At the same time, it takes charge of monitoring and answering the requirements of web client browser.

Because the various countries' graduate student management systems and management ways are different, the various countries' degree and graduate student education administration aspects also present the big differences. The domestic units raising graduate student usually make the degree and the graduate student education management information system in terms of their own raise pattern and the management characteristic. Viewing the graduate student education management information system the present various universities using, the following characteristic present:

(1) The degree and the graduate student education management information system lack the unified plan, each part of coordination is insufficient, data sharing between system and the integration is bad.

(2) The system service content is unitary. It mainly limits at the teaching administration, the academic record management, etc. However, there is almost not the information management system of directly unify the management of academic degree \& graduate education.

(3) The main bodies of the service object are superintendent or in-school graduate student. Few are management information system that serves teacher and provides the many service function for the society, particularly few based on the web. 
(4) The base data preparation insufficiency, the massive data dissociation outside the system. Both of them create the non-convenient use of the system.

Generally speaking, at present the degree and the graduate student education management information system and the degree and the graduate student education development have many inadaptable places.

The web-based management information system for academic degree \& graduate education can more efficiently adapt to the changing conditions and make inter-department more harmony and unification. What's more, it can realize remote information resource of graduate education management's sharing and management. It is the diligently informationization work direction of various degrees and graduate student education administration department, at present and the next section of times, to realize the information resource's sharing and management.

\subsection{Our Goals}

Unifying our actual work and work requirement, we have conducted the thorough research on the degree and graduate student education management information system, which based on the web. Through the service flow analysis of the degree and the graduate student, and carrying on the system demand analysis, we designed the scientific, standard, integrated highly, function-entirely, based-on-web degree and the graduate student education management information system. And this system has following characteristic:

First and most important, highly integrated, unified constructed data platform, is advantageous for the management and facilitates the application. It may cover each aspect of the Chinese degree and the graduate student education administration and serve.

Next, it takes each service flow and the main function design subsystem of the degree and the graduate student education as the central design subsystem, rather than the degree and the graduate student education administration department. For efficiency, it makes the organization's structure more flat.

Once more, the service object and the user of the traditional management information system mainly are the administrative personnel in the graduate student education. This design will implement the humanist thought. The service object expands and the graduate student, teacher will be the main body members who participate to use this system. It will also provide the service function for the society.

At present, we have realized such subsystem functions of this system: graduate student school register management, the raise plan and the curriculum manage, the raise project management, the result management, the degree management, the user jurisdiction management, etc. 


\section{Research and design}

\section{1 system analysis}

In order to design Web Information System for Academic Degree and Graduate Education, I use degree and graduate education of the HuaZhong normal university as the research subject.

\subsubsection{The Primary Service Analysis}

The main target of the degree and graduate student education management information system mainly is the discipline, the scholar, the students.

The discipline mainly was refers to have already to obtain the doctor degree and the master's degree authorization discipline specialty in the school. Under various disciplines has the basic situation to introduce, the troop constructs, the scientific research situation, the achievement and the prize situation, the key discipline, the key laboratory and so on.

The scholars mainly refer to the teacher to instruct the graduate student, including the graduate student instructor and the doctor instructor.

The students mainly refer to the graduate student in the school. It is to achieve the enrollment, training, degree management, student management, and employment of information management, in addition, also provide some of the information published on the Internet to collect and search functions, including enrollment plans of exam results in-school performance, degree and distribution of information.

\subsubsection{The System Goals}

Based on the above analysis, in order to meet school building and development needs, the system should meet the following development goals.

- System performance goals:

Usability: the management information system development should be the system's utility primary position, graduate education management information system design; the school should meet the graduate education management. The mechanism to operate should be in the first place.

Sophistication: Based on the pledge to meet the needs of the existing business, a certain system to maintain the advanced nature to make the system as growth in its life cycle. We must also consider the convenience of the system maintenance.

Integrity: the adoption of the system design and construction, so that the whole school graduate education information data reunification give full play to the entire system's overall efficiency.

Security: On the one hand we must guarantee the uniformity of the data and sharing, on the other hand we must guarantee the security of the data. Prevented the system suffers the attack and prevented the data is compiled to change and so on.

- The System Function Goal 
We establish one information platform to be able to cover the entire degree and graduate student education administration service work, to satisfy the different management level to each kind of information demand.

Operation to achieve the following major functions: Data input, including mass introduction; Data Processing, including scheduling, and statistics; Data output, including data is derived, data backup, statements and print form; Data inquiries to various conditions, and other forms of inquiry.

\subsubsection{System E-R figure}

This system refers to subject, scholar, graduate student, department, course, program, production, award, punish, and so on. The mostly substantiality in this system see Figure 1.

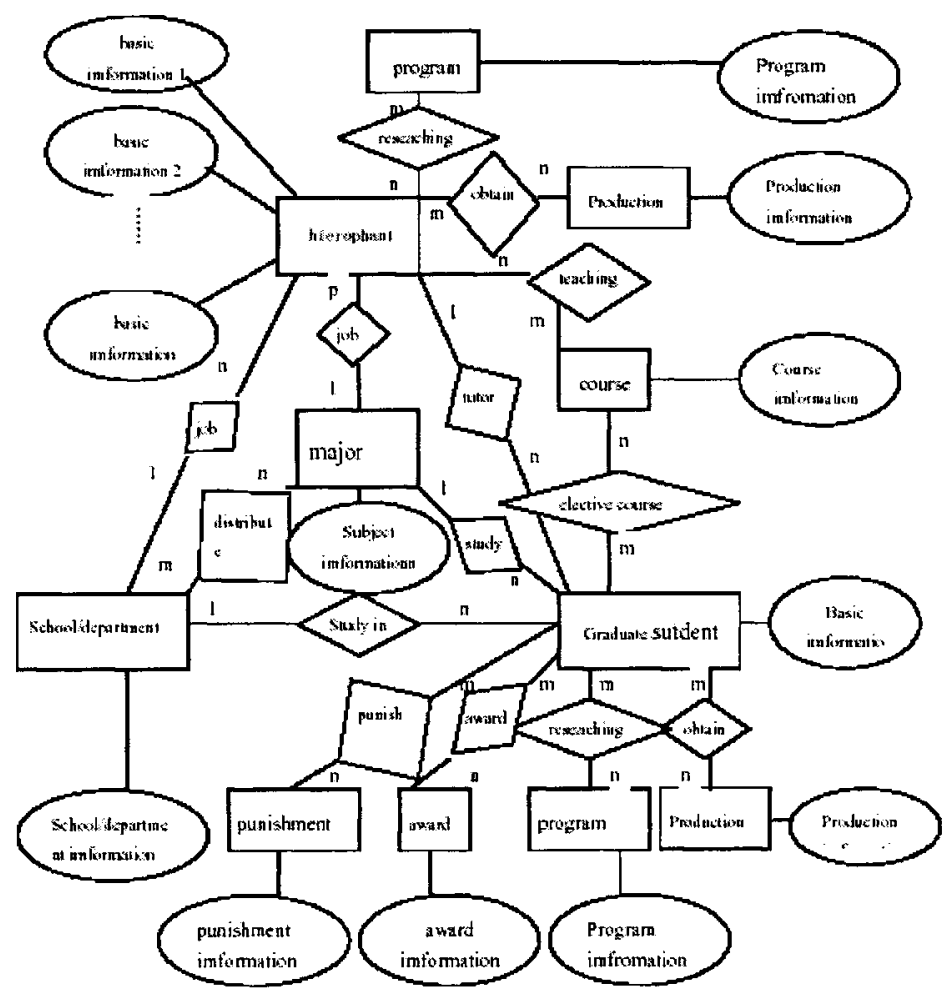

Figure 1 ADGEMIS mostly substantiality E-R figure 


\section{2 system design}

\subsubsection{Collectivity system design}

Information System refers to many parts and data. Its target is realization of a comparatively stable concerted management environment. When design it, at first should master the whole structure, seize the keystone, carve up the hierarchy, and then fractionize one by one. According to the each part of the Academic Degree and Graduate Education, carve up the whole system to 10 system: Subject management, hierophant management, School register management subsystem, training plan and course management subsystem, training plan management subsystem, score management subsystem, degree management subsystem, obtain employment management subsystem, basic information maintenance subsystem, user power management subsystem.

\subsubsection{System structure}

Design of Web Information System for Academic Degree and Graduate Education are shown in figure 2 .

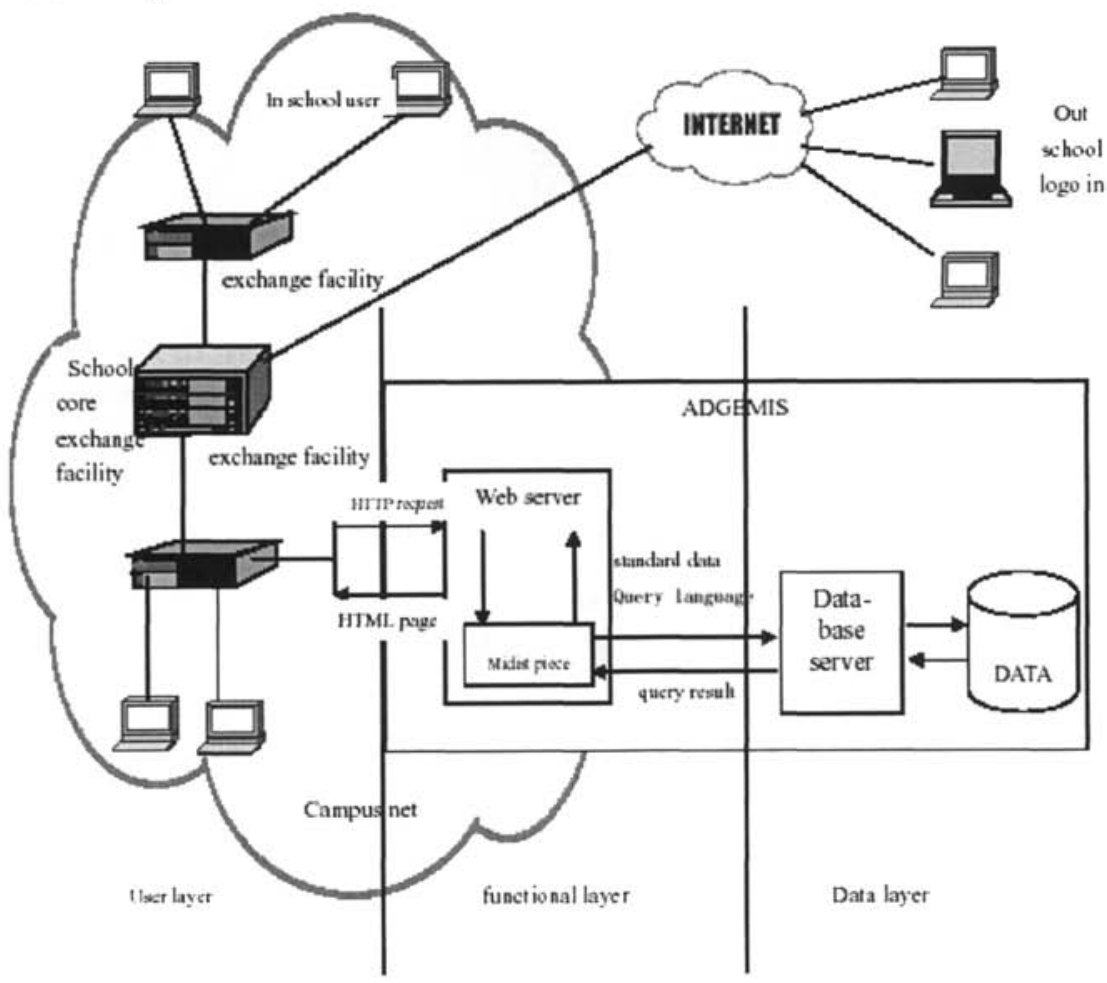


Figure2 system structure figure

In the database storage and handling of centralized storage and processing of information is centralized service model, academic degree and graduate education management information system (ADGEMIS) can be set up in graduate school (department), can be set up in schools center room. In the operating mode of using B/W/D framework internal and external users can through the web browser trip and academic degree and graduate education management information system (ADGEMIS).

The system is divided into user layer (also known as denote layer), the functional layer (also known as logic layer), the data layer, internal and external users through the use of the Internet web browser visits (including data maintenance and inquiry, etc.) for academic degree and graduate education Management Information System (ADGEMIS), HTTP request through the middleware layer functions (data transmission, analysis, processing, collating, sorting, printing and other functions) to the calling data server data requests, The database server will query result back to the function layer, the functional layer through the web browser will be back to the user.

\section{Realizations}

The academic degree and graduate education management information system has been realized and tested in the management of more than two thousand of grade 2006 graduate students in HuaZhong Normal University. The test and application includes the functions of recruiting graduates, academic record management, cultivating scheme management, constituting of individual cultivating plan, choosing course online, grade management and degree awarding management, etc. The fact proves that the system improved the work efficiency and service quality; the work period has averagely reduced $75 \%$. At the same time, it has been all-round tested the system's security, toughness, compatibility and integrality of database and redundancy, etc. At present, the system is running all right.

\section{Conclusions and Forecast}

Our web-based information management system has almost realized the functions of the subsystems of academic record management, cultivating scheme management, constituting of individual cultivating plan, choosing course online, grade management, degree awarding management, user power management, etc.

Khazanchi (2005) put forward a point of view that traditional match of "missiontechnique" is not equal to the improvement of mission performance. From the viewpoint of contingency theory to define math, it should use the match of "organization-technique" to answer the question of "when and in what condition does utilize the information technology to improve origination performance?" He put forward the conception of IT appropriateness. So we combine the experiences of study and development of information management system and consider that the following aspects should to note in the development of web-based information management system. 
(1) Research, design, development and management of information systems, must be "people-oriented" concept as a system design starting point and end-result; the system should obtain the support of collaborator.

(2) Research, design, development and management of information systems should give attention to both inter and outer origination's management and technique environment. At the same time, it should pay attention to the actual benefit after putting in practice of the system and the status of improvement of organization productivity, in order to perfect and adjust ceaselessly.

(3) Security strategies. Once the information system and network connectivity, it must consider the network and information systems security. Network and information systems security include physical security and logical security. Physical security is the use of network hardware, maintenance and management; logical security, mainly from the perspective of software made to the main data confidentiality, integrity and availability, and so on. The same time, must use the form of rules and regulations to manage information systems.

Computer technology, information technology and network technology to the rapid development both graduate and post-graduate education management with a daunting challenge, but also to improve our management to provide a good tool and means will further promote graduate education management information process.

Academic degree and graduate education is the vigorous development of colleges and universities to improve their level of the important links for building a "comprehensive research university" is a vital element.

Academic degree and graduate education management information system as a digital campus, part of the information, College to improve the management level, efficiency, service quality, proceed to raise academic standards and the quality of graduates will have farreaching significance.

\section{References}

1. W.M. Chen, H. Qi, Academic Degree and Graduate Education information management in information times. Academic Degree and Graduate Education, 2003(2)

2. X.J. Zhou, The Time transformation of the Academic Degree and Graduate Education. Educational Research and Experiment, 2005(1)

3. S.Q, Wang, etc. Study on the development of Management Information System for Graduate Education. Scientific \& Technical Information of GANSU, 2003(4)

4. X.C. Lu, Design and Implementation of Academic Degree Theses Management System Based on Web. Computer Knowledge and Technology, 2005(2)

5. W.P. Song, etc. Authorization of User Privilege on the Basis of Web Information System. Computer Engineering and Application, 2004(35)

6. The 1999 National Survey of Information Technology in US Higher Education: The Continuing Challenge of Instructional Integration and User Support.October,1999. The Compus Computing Project

7. Bieg, Claudial Diehl, Stephan .Educational and technical design of a Web-based interactive tutorial on programming in Java. Science of Computer Programming .2004, 53(1):25-36 
8. D. Khazanchi, Information Technology (IT) Appropriateness :The Contingency Theory of "FIT" and IT Implementation in Small and Medium Enterprises.The Journal of Computer Information Systems, 2005, 45(3):88-95

9. Bechtel Government Projects Estimating Standards Team., Bechtel's Proposed Approach to Baseline Ownership, Contingency, Rate and Escalation Applications on DOEProjects. March 24, 2000.

10. Bowman, C. Collier, Nardine, A contingency approach to resource-creation processes. International Journal of Management Reviews; Dec2006, Vol. 8 Issue 4, p191-211, 21 p 11. Organization and management: A Systems and Contingency Approach. 1985 by McGrawHill, Inc. 